\title{
Auditors’ Role, Responsibilities, Duties, and AIS to Prevent Errors and Frauds: An Evidence From Lebanon
}

\author{
Pierre Al-Khoury, Roula Moubarak, Maria Franjieh \\ Lebanese German University, Jounieh, Lebanon \\ Sarah Abboud \\ UNIFEL, Beirut, Lebanon \\ Mansour AlShamali \\ Public Authority for Applied Education and Training, Safat, Kuwait
}

\begin{abstract}
The paper is about how Lebanese auditors detect fraud in the course of their work and what they advise companies to implement in order to avoid fraudulent acts. For this purpose, various interviews were carried out from different experienced and well-reputed external auditors. This was also for their wide knowledge of all kinds of frauds. Data were taken from primary as well as secondary resources. The paper presents the theoretical and practical aspects. The theoretical part contains the accounting scandals, frauds, auditing processes, and auditor's responsibilities and tools for auditors to detect fraud. The practical part consists of case study analysis and detailed research processes.
\end{abstract}

Keywords: auditing, errors, frauds, duties of auditor, auditor responsibilities

\section{Introduction}

In October 2001, during an investigation by the Securities and Exchange Commission (SEC), a fraud was discovered in Enron practices. There was an overstatement of earnings and previously undisclosed debt obligation was also found. Arthur Andersen, the firm that audited the financial statements of Enron got involved in a debate as it was unable to show the improper accounting practices. Due to this, in August 2002, it had to officially cease its activities as an auditor and lost its reputation as being in the top five auditing companies in the US. A few more scandals were also revealed soon after Enron scandal. This was the reason why the confidence in the integrity of the entire system of public ownership and accountability in the US has deteriorated. The part of inspectors has not been very much characterized from the beginning (Alleyne \& Howard, 2005).

As indicated by ISA 240 and NSA 5, the essential obligation regarding the avoidance and discovery of extortion rests with both those accused of the substance's administration and the element's administration. ISA 240 and NSA 5 require the administration and those accused of administration to place an in number

Pierre Al-Khoury, vice president for development, General Management, Lebanese German University. Email: p.khoury@lgu.edu.lb.

Roula Moubarak, assistant for research projects, Business Office Department, Lebanese German University.

Maria Franjieh, accounting lecturer, Department of Business and Insurance, Lebanese German University.

Sarah Abboud, accountant, Accounting Department, UNIFEL.

Mansour AlShamali, head of Finance Department, Public Authority for Applied Education and Training. 
accentuation on misrepresentation counteractive action (to lessen open doors for misrepresentation), and extortion discouragement (to induce people not to submit misrepresentation by improving the probability of recognition and discipline).

Here, we will talk in detail about the frauds and errors. They are very similar. The whole economy is affected ultimately after the financial statements are harmed. Errors can be defined as the unintentional act of omitting an amount or a disclosure and fraud can be defined as: "the intentional act by one or more individuals among management, those charged with governance or third parties, involving the use of deception to obtain an unjust or illegal advantage” (Messier, Glover, \& Prawitt, 2007). There are further two types of frauds:

(1) Management fraud: It manipulates the financial reporting to deceive its users;

(2) Employee fraud: The employees steal the company property and resources through misappropriations of assets, such as embezzling received cash, stealing assets, and causing the entity to pay for goods and services not received.

Weirich and Reinstein (2000, as cited in Alleyne \& Howard, 2005) characterized extortion as "purposeful trickiness, swindling and taking”. Some regular sorts of extortion incorporate making imaginary loan bosses, "phantoms" on the finance, misrepresenting money deals, undeclared stock, making unapproved "benefits", and guaranteeing extreme or never-brought about costs.

Pollick (2006) saw extortion as a "purposeful deception, which makes one endure harms, generally money related misfortunes”. Albrecht et al. (1995, as cited in Alleyne \& Howard, 2005) characterized extortion into worker theft, administration extortion, speculation tricks, seller misrepresentation, client extortion, and random misrepresentation. Extortion likewise includes confused budgetary exchanges directed by desk lawbreakers, business experts with particular information and criminal goal (Pollick, 2006).

Financial statements are a main source of financial information as they tell the true financial position of the company and if there is a manipulation in the financial reporting does it have an immense cost? They damage the economy by leading investors and creditors to make unhealthy decisions and suffer major losses. They constitute a serious threat for investor's confidence in the quality, integrity, and credibility of the published financial reporting.

Financial statement users need assurance which can only be provided by auditors. They do this by planning and performing the audit, and they give an opinion about the fairness of the financial reporting. As per the definition of auditing, it is a systematic process of objectively obtaining and evaluating evidence regarding assertions about economic actions and events to ascertain the degree of correspondence between those assertions and established criteria and communicating results to interested users. It should be fairly represented as per the Generally Accepted Accounting Principles (GAAP).

Furthermore, Boynton, Johnson, and Kell (2005) and Oremade (1988) claimed that examiners are required to be more proactive in hunting down misrepresentation over the span of a review under ISA 240 (Revised). Their obligations now incorporate considering motivators and an open door exhibited to potential fraudsters, and in addition justifications that the false demonstration is supported. Inspectors are additionally anticipated that would ask all the more nearly into explanations for such matters as, for instance, lapses in bookkeeping appraisals, uncommon exchanges that seem to need a business method of reasoning, and a hesitance to remedy insignificant slips found by the review. 


\section{Research Thesis/Problem Statement}

This paper is about how Lebanese auditors detect fraud in the course of their work and what they advise companies to implement in order to avoid fraudulent acts.

\section{Limitations}

This study requires carrying out interviews with various experienced and reputed external auditors for their wide knowledge of all kinds of frauds.

We intended to interview the top eight auditing (Messier et al., 2007) firms in Lebanon, classified as such by the Ministry of Finance.

\section{Research Design}

This research study is based on data collected from the following firms representing the full population of national auditing firms in the country, without specified criteria since all of the working firms were contacted:

(1) CompuData - Orange Accounting;

(2) Professional Allied Auditors;

(3) Baker Tilly Zacca;

(4) LACPA;

(5) Horwath Abou Chakra \& Co.;

(6) Majzoub \& Co.;

(7) BECA Hatem \& Partners;

(8) BDO Fiduciaire du Moyent Orient.

The emails we sent to the auditors did not get a reply so we took a true Lebanese case study related to fraud detection. We also took an interview from a firm's manager along with his external auditor. He answered all the questions except those related to law issues.

\section{Research Tools}

Primary and secondary data were used. Secondary data were collected through journals, books, and online sources and primary data were collected from face-to-face interviews with two Lebanese auditors selected randomly and analysis of a real case. This was only to detect fraud.

\section{Thesis Structure}

The thesis was carried out in two parts:

(1) Theoretical part;

(2) Practical part.

The theoretical part contains the accounting scandals, frauds, auditing processes, auditor's responsibilities and tools to detect fraud. The practical part consists of a case study analysis and detailed research processes.

\section{Theoretical Part of This Research}

\section{Accounting Scandals}

There was a wave of accounting scandals between 2000 and 2005 due to which the working environment of auditors changed dramatically and got reshaped. The public accounting profession has shifted to the government regulation and oversight from the era of self-regulation only because of the series of scandals. This is the main reason why the accounting and auditing rules, regulations, and standards were made. 
The accounting scandals started with Enron in 2001. This was followed by a number of scandals and they were revealed as well. The following are some of these scandals:

(1) Corporate giants like WorldCom;

(2) Tyco International;

(3) Adelphia;

(4) Xerox.

There were a lot more firms who had the same story. The reaction to these scandals was very high. Congress as a reaction passed the Sarbanes-Oxley Public Company Accounting Reform and Investor Protection Act in July 2002 in an attempt to restore public confidence in the stock market.

\section{Public Company Accounting Oversight Board's (PCAOB) Responsibilities}

The Sarbanes-Oxley Act (SOX) called for the creation of the PCAOB, "a private-sector, non-profit corporation, to oversee auditors of publicly traded companies in order to protect the interests of investors and further the public interest in the preparation of informative, accurate, and independent audit reports" (PCAOB, 2014).

The PCAOB is a charitable enterprise set up by Congress to regulate the reviews of open organizations with a specific end goal to ensure financial specialists and the general population enthusiasm by advancing enlightening, exact, and autonomous review reports. The PCAOB additionally manages the reviews of specialists and merchants, including consistence reports documented as per government securities laws, to advance speculator insurance.

The SOX of 2002, which made the PCAOB, required that evaluators of US open organizations be liable to outer and autonomous oversight without precedent for history. Already, the calling has been self-managed.

\section{Accounting Firms' Requirements and Proscriptions}

There are certain requirements and prohibitions placed on accounting firms by the act. It is a law for all the public audit firms to get registered with the board before they audit.

Prominent accounting scandals in the mid-2000s (e.g., Enron, WorldCom) proposed that letting bookkeepers "counsel" for review customers bargains evaluator autonomy, and hence lessens profit quality (e.g., see Romano, 2004; Weil, 2004): (1) Citing such cases, US officials overwhelmingly bolstered the SOX of 2002, a piece of which limits inspectors from delivering non-review administrations (NAS); and (2) Research on divulgence orders that went before SOX, then again, delivered little proof that business sectors esteem data about how intensely bookkeepers rely upon their review customers for counseling charges (e.g., see Glezen \& Millar, 1985; Frankel, Johnson, \& Nelson, 2002; Ashbaugh, LaFond, \& Mayhew, 2003), and powered academic protests to revelation commands, as well as proscriptive regulations like SOX (e.g., see DeFond, Raghunandan, \& Subramanyam, 2002).

Maybe all the more critically, we additionally assess conceivable channels through which a review customer's exposure or administration decisions may make outside impacts. This kind of exact assessment seems new to the writing, and in this manner encourages more sure regularizing decisions about proscriptive administration regulations. Here, we find that market discipline (may be upgraded by divulgence commands) presumably left no place for SOX banishments on NAS to enhance money-related business sector execution. 


\section{Generally Accepted Auditing Standards}

Until 2003, the Auditing Standards Board (ASB) was responsible for establishing auditing standards for all non-governmental audits. However, after passing the SOX, the Congress transferred that authority to the PCAOB.

The PCAOB adopted the 10 Generally Accepted Auditing Standards (GAAS) set by the ASB in 1947. It had modified them to meet the auditor's environment and referred to them as "the standards of the PCAOB", and in a book entitled Auditing \& Assurance Services: A systematic Approach, Messier et al. (2007) grouped GAAS into three categories:

(1) Category 1: General standards;

(2) Category 2: Standards of field work;

(3) Category 3: Standards of reporting.

These three general categories are concerned with the auditor's qualifications and the quality of his work. The first general standards require the auditor to have an adequate training and proficiency gained through formal education, continuing education programs, and experience. The second general standards are concerned with the independency and objectivity of the auditors in performing the audit process. The third general standards focus on the due professional care, which means that the auditor must perform his duties with the skills and care prescribed in the code of practice of his profession.

\section{Types of Frauds}

Fraud is committed either by the management, the employees, or by those charged with governance ${ }^{1}$, such as $\mathrm{CEO}$ and $\mathrm{CFO}$ :

(1) The preparation of financial statements through inaccurate data gathering or processing;

(2) The non-conformity of financial statement amount, classification, presentation, or disclosure to the GAAP;

(3) The omission of an element, amount, or item in the financial statements;

(4) The omission of some information that should be disclosed in conformity with GAAP;

(5) The inaccurate accounting estimation resulting from an oversight or misinterpretation of facts;

(6) The auditor's belief in the unfairness or the inappropriateness of the management's judgments regarding an accounting estimation, selection, or application of accounting procedures.

\section{Incentives for Committing Fraud}

Perpetrators of accounting frauds generally start with small deception and then get larger as they gain confidence after getting away with their first dishonest act. Therefore, internal and external audits may hold them back from committing frauds.

\section{Understanding the Entity and Its Environment}

This section aims at assessing the business risks faced by the entity and evaluating the management response to those risks in order to identify the misstatements that might result from errors or fraud.

Understanding the entity's environment requires the auditor to have knowledge about the following:

(1) Industry, regulatory, and other external factors;

\footnotetext{
${ }^{1}$ A term used to describe the role of a person entrusted with the supervision, control, and direction of an entity.
} 
(2) Nature of the entity;

(3) Objectives, strategies, and related business risks;

(4) Measurement and review of the entity's financial performance.

\section{Evaluating and Testing the Internal Control}

According to the Committee of Sponsoring Organizations (COSO), internal control:

Is designed and affected by the entity’s BOD, management, and other personnel to provide reasonable assurance about the achievement of the entity's objectives regarding the reliability of financial reporting, the effectiveness and the efficiency of operations, and the compliance with applicable, laws and regulations. (Messier et al., 2007)

\section{The Auditor's Responsibility to Detect and Report Errors and Irregularities}

In October 1987, the National Commission on Fraudulent Financial Reporting recognized that fraud and its consequence are the responsibility of many parties, including BOD, management, internal and external auditors. The Commission approved that independent auditors are not able to guarantee the accuracy and consistency of financial information. However, their role could be particularly enhanced with respect to fraudulent financial reporting. In 1988, the ASB issued SAS No. 53 to clarify the auditor's role and to respond to public misconceptions. The most common misconceptions assume that auditors will:

(1) Discover all material errors and irregularities in the financial statements;

(2) Detect all illegal acts committed by customers;

(3) Confirm the entity's financial health.

\section{Consideration of Fraud in a Financial Statement Audit (SAS No. 99)}

In November 2002, the AICPA issued SAS No. 99 to:

(1) Correct some of the shortcomings of SAS No. 82;

(2) Restore the investors' confidence in stock market;

(3) Reduce the incidence of financial fraud.

\section{Tools to Detect Fraud: The Red Flags}

Following SAS No. 99, auditors entered an extended arena of procedures to detect fraud. They must now gather and consider much more information when assessing fraud risk. One of the procedures is the use of "Red Flags" which are considered as fraud indicators. Red flags are a set of unusual circumstances indicating that something out of the ordinary is happening. They are not absolute, but should be investigated to ensure that fraud does not exist.

They are classified as:

(1) Employee and/or management behavior changes;

(2) Cash receipt process;

(3) Accounts receivable process;

(4) Inventory/production process;

(5) Purchasing process;

(6) Accounts payable process;

(7) Payroll process. 


\section{Applied Theory}

\section{Real Lebanese Case}

Time and place. The case is a factual one that occurred in June 2013. Two people in the catering business admitted a silent partner as a third member for a seasonal business venture in May 2013. The capital consists of 260,000 USD, divided as follows:

(1) Partner X: 80,000 USD;

(2) Partner Y: 80,000 USD;

(3) Partner W: 100,000 USD.

People involved. The people involved for research are as follows:

(1) The partners who will be referred to as follows:

(a) Partner one: $X$;

(b) Partner two: Y;

(c) Partner three (the silent partner): W.

(2) The auditors of:

(a) Partner W;

(b) Partners X and Y.

(3) Resort employees:

(a) The floor manager;

(b) The janitor.

(4) The IT expert in the computer software company which designed the accounting system.

Type of fraud. The type of fraud committed in this case is the misappropriation of assets.

The fraud tools. The tools used here are the following:

(1) The user FOUR in the accounting software used in the partnership;

(2) The bank account.

\section{Conflict Resolution}

Partners $\mathrm{X}$ and $\mathrm{Y}$ confessed that they were committing fraud and cheating their silent partner. It was agreed with their auditor that partner $\mathrm{W}$ would be paid his share of the profits for the whole season in addition to $10 \%$ damages. Naturally, partner $\mathrm{W}$ withdrew from the partnership and was granted a legal absolution.

This case study emphasizes the role of the auditor in detecting fraud. It also raises the need for auditors to acquire basic computer skills and AIS know-how in addition to their accounting experience.

AIS software must include segregation of duties. This issue will be brought up in the interview section. On the other hand, developed and updated software helps auditors to prevent and automatically avoid employees' fraud.

Consequently, preventing and minimizing fraud will lead to easy fraud detection.

When creating a user in the AIS for training purposes, restrictions should be applied. These may include:

(1) User four must be used once a week and for a limited number of entries;

(2) The amounts recorded must have ceilings.

\section{Interview's Questionnaire}

The interview consists mainly of three parts. The first one entitled "Types of Fraud", comprising the following four questions: 
(1) What are the types of fraud frequently encountered?

(2) What are the most repetitive types?

(3) Is there a particular reason for them to be so frequent?

(4) How often is fraud encountered?

The second category entitled "Fraud Detection and Prevention Methods", answering the following two questions:

(1) How do you detect and prevent such fraud?

(2) How costly is the process of fraud detection?

As for the last part entitled “Auditors’ Responsibilities for Fraud Detection”, it includes two questions:

(1) Do you think that auditors sometimes participate in covering up a fraud?

(2) Are auditors accountable for covering up a fraud? Is there a law concerning this?

As mentioned in the introduction, we had tried to meet several audit firms' managers, either by email or phone calls. Unfortunately, they were either not available or chose not to reply at all. This is the reason why we conducted the interview with the one and only firm manager who answered back with enthusiasm.

\section{Auditor's Response}

After a quick and warm welcome, we were told that Bassil Audit Firm has more than 15 years of experience in this field. Its existing target clients belong to small, medium, and big size companies operating in many domains.

\section{Conclusion}

This research identified the importance of auditors' role in detecting fraud. However, due to restrictions in time and cost, any audit process is conducted to provide only reasonable assurance that the financial statements are free of material misstatements. Moreover, internal control and AIS play a major role in establishing a strong organization structure that leads to its success. Consequently, management has to identify and evaluate all risks faced by the entity to create efficient controls that achieve the company's objectives and prevent fraud.

\section{Recommendation}

Detecting and preventing fraud must constantly present strategic plans and decisions in all organizations. Top management should place a greater emphasis on creating a strong internal control system. It also has to review those controls on a regular basis. As seen in this research, AIS is responsible for providing timely and accurate financial reporting.

Computer technology represented by AIS plays an important role in preventing, detecting, and committing fraud. This is the reason why management must always ensure its accuracy and reliability to ban perpetrators from using it for their fraudulent act. Consequently, auditors should acquire an excellent know-how in computer skills and awareness of the AIS.

ACL Company's software product may also be considered as an audit prevention method. ACL Company aims to empower internal controls by enlarging the scopes of audit risk management through combination of software and expert content.

They have an online video that helps teams to become more audit efficient and to save time. Their software standardizes and simplifies audit tasks. By doing so, they increase the team yield and efficiency up to $50 \%$. It permits to perfectly integrate the industry's standard data into a full risk assessment.

By visiting their website, auditors can enhance their knowledge about technological solutions. 


\section{References}

Alleyne, P., \& Howard, M. (2005). An exploratory study of auditors' responsibility for fraud detection in Barbados. Managerial Auditing Journal, 20(3), 284-303.

Ashbaugh, H., LaFond, R., \& Mayhew, B. W. (2003). Do nonaudit services compromise auditor independence? Further evidence. Accounting Review, 78(3), 611-639.

Boynton, W., Johnson, R., \& Kell, W. (2005). Assurance and the integrity of financial reporting (8th ed.). New York, NY: John Wiley \& Sons, Inc..

DeFond, M. L., Raghunandan, K., \& Subramanyam, K. R. (2002). Do non-audit service fees impair auditor independence? Evidence from going concern audit opinions. Journal of Accounting Research, 40(4), 1247-1274.

Frankel, R. M., Johnson, M. F., \& Nelson, K. K. (2002). The relation between auditors' fees for nonaudit services and earnings management. Accounting Review, 77, 71-105.

Glezen, G. W., \& Millar, J. A. (1985). An empirical investigation of stockholder reaction to disclosures required by ASR No. 250. Journal of Accounting Research, 23(2), 859-870.

Messier, W. F., Glover, S. M., \& Prawitt, D. F. (2007). Auditing \& assurance services: A systematic approach (6th ed.). New York, NY: McGraw-Hill/Irwin.

Oremade, T. (1988). Auditing and investigation. Lagos: West African Book Publishers.

Pollick, M. Y. (2006). What is fraud? Retrieved from http://www.wisegeek.com/what-is-fraud.htm

Public Company Accounting Oversight Board [PCAOB]. (2014). The auditors of companies to protect investors. Retrieved from http://pcaobus.org/Pages/default.aspx

Romano, R. (2004). The Sarbanes-Oxley Act and the making of quack corporate governance. New York University Law and Economics Working Papers, No. 3.

Weil, J. (2004, March 31). Auditing firms get back to what they do best. Wall Street Journal, C3.

Weirich, T. R., \& Reinstein, A. (2000). Accounting \& auditing research: A practical guide. Dayton, OH: South-Western College Publishing. 